\title{
PENGOLAHAN SAMPAH ORGANIK MENJADI KOMPOS UNTUK MENDUKUNG KAMPUNG PRO IKLIM
}

\author{
Normela Rachmawati, Susilawati, Eva Prihatiningtyas \\ Fakultas Kehutanan, Universitas Lambung Mangkurat \\ Email : $\underline{\text { susi_unlam@yahoo.co.id }}$
}

\begin{abstract}
Trash is a major problem in Banjarbaru City thus far. The trash volume in Banjarbaru approximately 120 tons per day on year 2017-2018 and that goes to landfill thereabouts 105 tons. Therefore, it is important manage the household waste, so do on community level through "Bank of Trash" as an efforts in creating a Pro Climate (PROKLlM) hometown. Household waste management success through Bank of Trash as one of the efforts of creating "Kampung Proklim" is influenced by the level of knowledge and skill of group manager, waste management technology that mastered, management of waste, community support and the participation of other institutions. The General conditions of the Bank Trash Benawa Raya Mandiri (BRM) is quite adequate, but merely collecting and selling inorganic garbage from citizens around settlement of Benawa Raya Mandiri to the Gatherer, on the other hand, organic waste is available in abundance in settlement area of Benawa Raya Mandiri, so it consider to be necessary to open such group counselling and training to transfer knowledge and technology to process the organic waste become compost.
\end{abstract}

Keywords: Bank of Trash, Pro Climate Hometown, Compost

\begin{abstract}
ABSTRAK
Sampah masih menjadi persoalan utama Kota Banjarbaru. Volume sampah Kota Banjarbaru tahun 2017 - 2018 sekitar 120 ton per hari dan yang masuk ke TPA sekitar 105 ton. Oleh karenanya harus dilakukan pengelolaan sampah di tingkat rumah tangga dan masyarakat melalui Bank Sampah sebagai salah satu upaya dalam menciptakan kampung Pro lklim (PROKLlM). Keberhasilan pengelolaan sampah rumah tangga melalui Bank Sampah sebagai salah satu upaya menciptakan Kampung Proklim dipengaruhi oleh tingkat pengetahuan dan keterampilan kelompok pengelola sampah,teknologi pengelolaan sampah yang dikuasai, manajemen pengelolaan sampah, dukungan masyarakat dan partisipasi lembaga lain. Kondisi umum Bank Sampah Benawa Raya mandiri (BRM) cukup memadai, namun hanya mengumpulkan dan menjual sampah anorganik dari warga Komplek Benawa Raya ke pengepul, di sisi lain, sampah organik tersedia melimpah di Komplek Benawa Raya sehingga diperlukan penyuluhan dan pelatihan transfer ipteks untuk pengolahan sampah organik menjadi kompos.
\end{abstract}

Kata kunci: Bank Sampah, Kampung Pro Iklim, Kompos 


\section{PENDAHULUAN}

Persoalan sampah menjadi PR besar seluruh kota kota di Indonesia tidak terkecuali kota Banjarbaru. Apalagi dengan makin bertambahnya jumlah penduduk kota yang berjuluk kota idaman. Volume sampah kota Banjarbaru tahun 2017 - 2018 perhari menghasilkan sekitar 120 ton dan yang masuk 105 ton. Sisa sampah tersebut dapat diolah masyarakat melalui daur ulang. Volume sampah di Banjarbaru cenderung mengalami kenaikan setiap tahun, disebabkan penambahan jumlah penduduk dan adanya pemindahan pusat pemerintahan provinsi Kalimantan selatan ke Banjarbaru.

Sampah-sampah yang masuk ke TPA Gunung Kupang pada tahun 2017 mencapai 39.620 ton. Pengangkutan sampah oleh Dinas Lingkungan Hidup kota Banjarbaru menggunakan 41 armada truk yang menjemput sampah sampah dari 120 TPS yang tersebar di kota Banjarbaru.

Sedangkan untuk sampah yang tidak terlayani dilakukan dengan pengangkutan ekstra secara berkala pada lokasi-lokasi pembuangan sampah liar dan TPS-TPS yang melebihi kapasitas tampungan sampahnya. Bahkan tiap tahunnya dilakukan penambahan armada truk. Namun, jumlah sampah yang diangkut tidak berkurang. Karena itu perlu ada upaya untuk mengurangi timbunan sampah dari sumbernya, yaitu dari warga masyarakat sendiri. Untuk itu, perlu ada upaya pengelolaan sampah, khususnya dengan sistem 3R, Reuse-ReduceRecyc/e.

Untuk pengelolaan sampah diperlukan peningkatan kesadaran dan partisipasi masyarakat dalam pelaksanan TPS 3R, dalam hal ini masyarakat diminta kesadarannya untuk terlebih dahulu memilah sampah, antara sampah organik dan anorganik. Program ini sudah disosialisasikan kepada masyarakat oleh dinaslinstansi terkait. Namun belum terlihat perubahan yang signifikan dalam mengatasi permasalahan sampah.

Sampah berpotensi memberi sumbangan terhadap meningkatnya emisi gas rumah kaca, akibat penumpukan sampah tanpa diolah dapat melepaskan gas methane (CH4) . Setiap 1 ton sampah padat menghasilkan $50 \mathrm{~kg}$ gas CH4. Jika perkiraan sampah yang dihasilkan di Banjarbaru pada tahun 2017 mencapai 120 ton, maka jumlah gas $\mathrm{CH} 4$ yang diemisikan ke atmosfir diperkirakan mencapai $6000 \mathrm{~kg}$. 
Gas CH4 memiliki potensi merusak 20 kali lebih besar dari gas C02. Untuk mengurangi dampak sampah terhadap perubahan iklim, perlu dilakukan kegiatan pengelolaan sampah di tingkat rumah tangga maupun masyarakat (Bank Sampah). Hal ini juga merupakan salah satu upaya mitigasi perubahan iklim dalam menciptakan Kampung Pro Iklim (PR0KLIM). Kegiatan mitigasi perubahan iklim yang dapat dilakukan antara lain : a) pewadahan dan pengumpulan sampah di tingkat rumah tangga ataupun masyarakat (bank sampah) dengan menyediakan tempat sampah yang layak b) menyediakan instalasi pengolahan sampah di tingkat masyarakat melalui Bank Sampah dapat dikelola dengan baik c) Memanfaatkan hasil pengolahan seperti kompos atau kerajinan yang dapat dijual. Upaya mitigasi perubahan iklim dengan pengelolaan sampah ini selain dapat menciptakan lingkungan yang bersih dan sehat, juga dapat mengurangi sampah sebesar $50 \%$ - $60 \%$ dari timbunan sampah yang dihasilkan rumah tangga.

Tujuan dari kegiatan pengabdian ini adalah dapat melakukan transfer teknologi yang tepat kepada masyarakat khususnya ibu ibu yang tergabung dalam Bank Sampah Benawa Raya Mandiri (BRM) dalam upaya partisipasi mengurangi volume sampah rumah tangga di sekitar Komplek Benawa Raya Banjarbaru.

Kegiatan ini diharapkan meningkatkan ipteks dan produktivitas mitra dalam mengolah sampah organik sehingga bernilai secara ekonomi. Bagi tim pengabdian sendiri, kegiatan ini merupakan wujud peningkatan atensi akademis terhadap masyarakat khususnya pengurus bank sampah BRM sehingga dapat menjadi project percontohan untuk masyarakat sekitar komplek. Dengan adanya kegiatan ini, membuka peluang dan kesempatan bagi tim pengabdi untuk dapat mengaplikasikan ilmu bagi kepentingan masyarakat sebagai bentuk nyata dari pelaksanaan kegiatan Tri Dharma Perguruan Tinggi, yaitu Pengabdian pada Masyarakat.

\section{METODE PENGABDIAN}

Beberapa tahapan metode pengabdian yang diterapkan untuk keberhasilan kegiatan pengabdian ini antara lain :

a. Sosialisasi Awal (Penyuluhan dan Diskusi) ; Penyampaian materi 
teoritis oleh tim pengabdi kepada khalayak sasaran (ibu ibu yang tergabung dalam Bank Sampah BRM), dengan diskusi aktif dua arah. Kegiatan penyuluhan dengan mengikutsertakan peserta dalam setiap topik yang dibicarakan dan diharapkan muncul banyak saran, tanggapan, pertanyaan dan pendapat dari peserta (curah pendapatlbrain storming). Metode ini diharapkan mampu menarik minat lebih tinggi peserta untuk selalu ingin tahu dan mempercepat proses adopsi teknologi yang disuluhkan. Adapun materi yang diberikan yaitu tentang pemilahan sampah organik dan anorganik, pengetahuan tentang kampung pro iklim (proklim), kegiatan yang dapat dilakukan dalam mitigasi perubahan iklim, pemanfaatan sampah organik menjadi kompos.

b. Pelatihan pembuatan kompos dari sampah organik rumah tangga, dilakukan praktek secara langsung, pengolahan sampah organik (sisa sayuran, buah yang merupakan sampah organik rumah tangga) menjadi kompos. Persiapan alat dan bahan untuk pengolahan, pelaksanaan proses dekomposisi dilakukan dengan mengikutsertakan peserta kegiatan. Bahan organik dicacah terlebih dahulu di mesin pencacah, kemudian dimasukkan dalam komposter. Bahan organik dicampur dengan kotoran ternak, sekam padi, EM4. Setiap 3 hari, campuran tersebut dibolak balik agar mendapatkan panas merata (proses fermentasi). Setelah kurang lebih 3 (tiga) minggu kompos siap dipanen.

c. Kegiatan pengomposan yang dilakukan oleh anggota Bank Sampah Benawa Raya Mandiri sendiri tanpa bantuan tim pengabdi. Pengabdi hanya sebagai tim pengamat.

d. Pendampingan proses fermentasi sampai kompos siap digunakan

e. Pemantauan dan Evaluasi Kegiatan dibarengi dengan penelusuran sikap dan keinginan mitra secara langsung maupun tidak langsung yaitu melalui alat bantu kuisioner yang dilakukan sebelum dan sesudah kegiatan yang dapat mengakomodir tingkat penguasaan, keberlanjutan, dan pemahaman terhadap seluruh kegiatan yang diberikan. Data yang diperoleh 
dikumpulkan dan dianalisis secara deskriptif

\section{HASIL DAN PEMBAHASAN}

1. Sosialisasi dan Penyuluhan

Mitra yang menjadi sasaran adalah ibu ibu Pengurus Bank Sampah Benawa Raya Mandiri, diharapkan mereka dapat menularkan pengetahuan yang mereka miliki kepada ibu ibu lainnya. Pada saat kegiatan sosialisasi dan penyuluhan, dari sasaran target terpenuhi $100 \%$ yaitu dengan kehadiran peserta sebanyak 15 orang. Dalam tahapan ini berhasil diperoleh data bahwa pengetahuan mereka tentang Penge/0/aan Sampah sangat minim, hal ini dapat dilihat pada label 1.

Label 1. Pengetahuan Umum tentang Pengelolaan sampah Sebelum dan Sesudah Sosialisasi Penyuluhan

\begin{tabular}{llllll}
\hline No & Jenis Pertanyaan & \multicolumn{3}{l}{ Jumlah Anggota (Orang) } \\
\cline { 3 - 5 } & & \multicolumn{3}{l}{ Tahu } & \multicolumn{3}{l}{ Tidak Tahu } \\
\cline { 3 - 5 } & & Sebelum & Sesudah & Sebelum & Sesudah \\
\hline 1 & Pernah Mengetahui tentang & - & 15 & 15 & - \\
& Kampung & 5 & 15 & 10 & - \\
2 & Pengolahan Kompos & 1 & & 14 & \\
3 & Pengolahan MOL & 1 & 15 & 14 & - \\
\hline
\end{tabular}

Dari jawaban yang diberikan terhadap pertanyaan yang sama sebelum maupun sesudah pelaksanaan sosialisasi dan penyuluhan menunjukkan bahwa materi yang diberikan sangat dipahami dan hal tersebut menunjukkan keberhasilan kegiatan. Mitra sangat antusias terhadap kegiatan, ini ditandai dengan rasa semangat dan antusiasme mitra, aktifnya peserta yang terlibat diskusi terkait pengelolaan sampah di lingkungan perumahan Benawa Raya dan tumbuhnya semangat berwirausaha melalui sampah. 


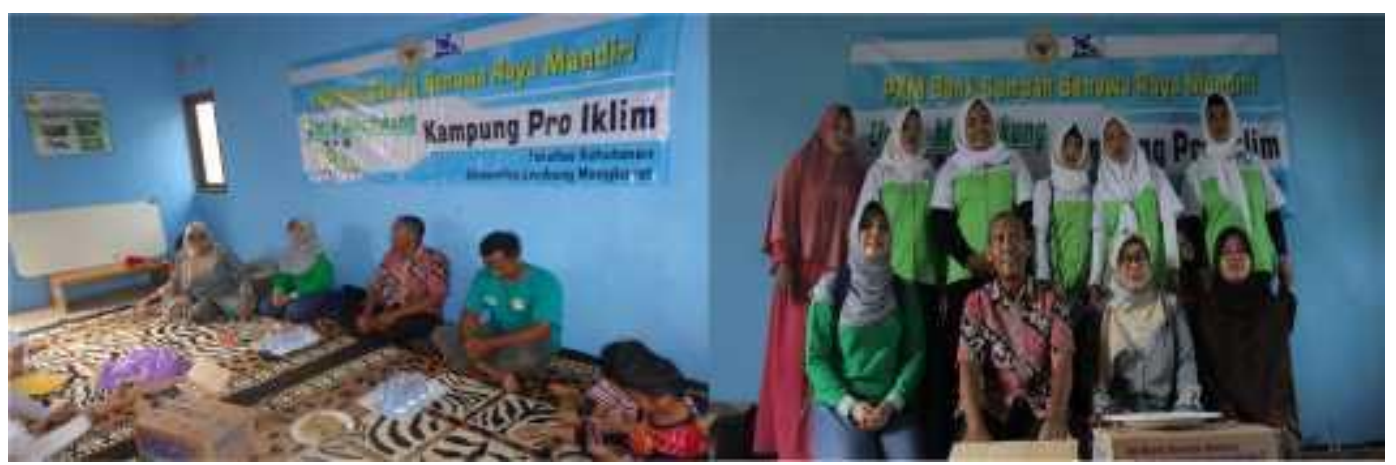

Gambar 1. Penyuluhan mengenai pengelolaan sampah di Komplek Benawa Raya

Diskusi tentang kampung prO iklim terasa sangat menarik karena dikaitkan dengan isu kerusakan lingkungan. Ibu ibu dapat mengurangi kerusakan lingkungan dimulai dari hal hal yang kecil yaitu dengan memperlakukan sampah dengan metode 3R (Reuse, reduce, dan recycle). Penerapan 3R menjadi salah satu solusi dalam menjaga lingkungan yang mudah dan murah untuk dilakukan disamping mengolah sampah menjadi kompos atau memanfaatkan sampah menjadi sumber listrik. Pelatihan pemanfaatan pekarangan dengan penanaman sayuran dan toga dilakukan juga di bank sampah BRM, kegiatan ini diharapkan menggugah keinginan ibu ibu lainnya agar dapat memanfaatkan lahan pekarangan semaksimal mungkin sehingga dapat memenuhi kebutuhan akan sayuran bagi keluarga. Diharapkan bank sampah menjadi tempat informasi bagi masyarakat sekitar dalam hal pemanfaatan sampah baik organik maupun anorganik.

2. Pelatihan

Kegiatan pelatihan pembuatan kompos, berjalan dengan lancar. Peserta berperan aktif dalam mempersiapkan sebagian bahan dan peralatan yang diperlukan pada kegiatan ini atas inisiatif mereka sendiri. Setiap sesi pelatihan pengolahan sampah diperhatikan peserta dengan baik, bahkan para peserta tanpa ragu langsung mencoba melakukan sendiri setiap langkah yang terdapat dalam modul pelatihan. Peserta dapat menguasai hampir $80 \%$ ketrampilan yang diberikan.

Mengingat sampah organik selalu tersedia setiap saat dan pengolahannya cukup mudah, maka pengolahan sampah organik menjadi kompos bisa 
kapan saja dilakukan. Jika ditinjau dari sisi ketersediaan bahan baku dan kemudahan mengolahnya, usaha pengolahan kompos ini memiliki peluang bisnis untuk dikembangkan.

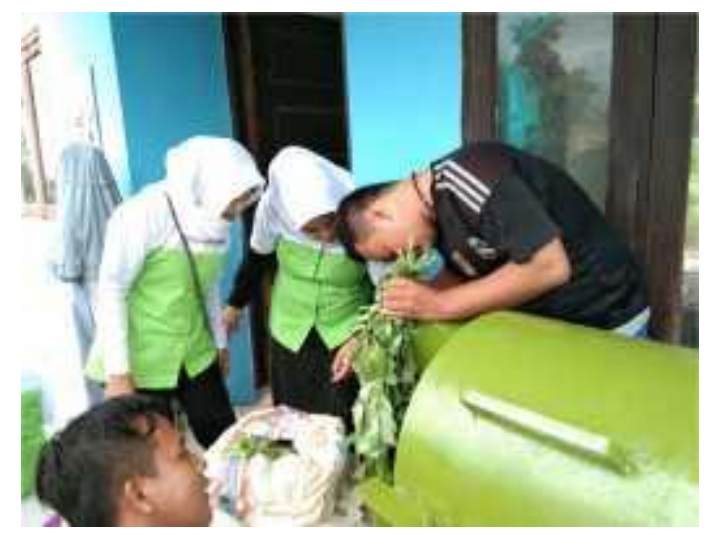

Pengolahan kompos dari bahan organik sangatlah mudah untuk diolah. Pada pelatihan ini digunakan bekas sayuran, sampah dedaunan, kotoran ternak, jerami, sekam dan EM4.

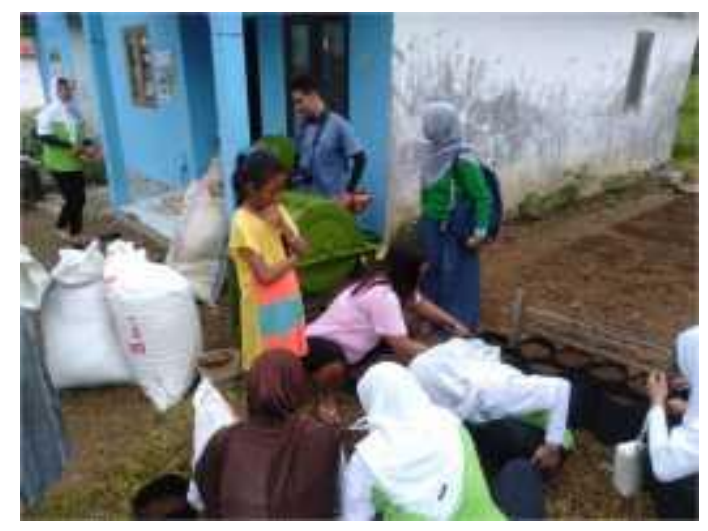

Gambar 2. Pelatihan pembuatan kompos dan penanaman sayuran di polybag

\section{Pendampingan}

Kegiatan

pendampingan

dilakukan untuk memotivasi para peserta untuk berani memulai setiap langkah yang berbentuk kewirausahaan atau melakukan suatu kegiatan walaupun dalam skala kecil. Kegiatan pendampingan berjalan dengan lancar. Setiap seminggu sekali, tim pengabdi membantu peserta memeriksa proses pengomposan dengan cara membolak balik serasah dan memberikan air jika dirasa kering. Hal ini dilakukan sampai suhu sampah organik yang didalam terpal menjadi suhu normal. Peserta juga berkewajiban memelihara sayuran dan IOGA yang ditanam di bank sampah agar berkembang dengan baik. Kegiatan pengolahan kompos yang dilaksanakan di pekarangan Rumah Organik Bank Sampah Benawa Raya Mandiri diharapkan berjalan maksimal dan menumbuhan jiwa wirausaha peserta.

4. Pemantauan dan Evaluasi

Agar kegiatan pengabdian ini terarah dan kontinyu maka dilaksanakan pemantauan dan evaluasi. Berdasarkan hasil evaluasi kegiatan PKM terjadi peningkatan kesadaran masyarakat dalam pembuangan dan pengelolaan sampah rumah tangga mencapai $80 \%$. Pembuatan kompos di Bank Sampah benawa Raya sudah 
mendapatkan sentuhan teknologi yaitu menggunakan alat pencacah. Hasil pelatihan dan pendampingan menunjukkan bahwa para pengelola Bank Sampah BRM sangat antusias untuk meningkatkan pengetahuan dalam pengelolaan sampah melalui pengomposan, ini merupakan modal dalam pengelolaan sampah selanjutnya. Untuk meningkatkan kualitas kompos yang dihasilkan akan dilakukan pendampingan secara berkelanjutan. Diperlukan juga dukungan dari Pemerintah Kota Banjarbaru sampai Bank Sampah ini dapat berjalan dengan baik dan mandiri. Berdasarkan Peraturan Menteri Negara Lingkungan Hidup RI (2012) tentang Kampung Iklim. Pengelolaan sampah di BRM merupakan salah satu upaya mitigasi perubahan iklim untuk menurunkan tingkat emisi gas rumah kaca sebagai bentuk upaya penanggulangan dampak perubahan iklim.

\section{KESIMPULAN}

Hasil kegiatan yang dilakukan tim pengabdi dapat disimpulkan a) Peningkatan kesadaran ibu ibu pengurus Bank Sampah Benawa Raya dalam hal pembuangan dan pengelolaan sampah mencapai $80 \%$ b) Para pengurus Bank
Sampah BRM sangat antusias untuk meningkatkan pengetahuan dalam pengelolaan sampah sebagai upaya mendukung program Kampung Pro iklim c) Dukungan Pemerintah Kota Banjarbaru masih sangat diperlukan khususnya Dinas Lingkungan Hidup Kota Banjarbaru melalui sosialisasi informasi, pendampingan dan penyuluhan yang dilakukan secara berkelanjutan agar Bank Sampah BRM dapat mandiri.

\section{UCAPAN TERIMA KASIH}

Ucapan terima kasih disampaikan kepada Kementerian Riset, leknologi dan Pendidikan linggi atas pendanaan melalui skim Program Kemitraan Masyarakat tahun 2019.

\section{DAFTAR PUSTAKA}

Anonim. 2005. Pengolahan Sampah. Pustekom.www.edukasi.net.(diaks es tanggal 2 Maret 2009

Anonim. 2009. Pembuatan Kompos dan Permasalahannya.www.wikipedia .com.

Soeleman,S dan Rahayu,D. 2013. Halaman Organik. AgroMedia Pustaka. Jakarta.

Sulistyorini, L. 2005. Pengolahan Sampah Organik dengan Cara Menjadikannya Kompos. Jurnal

Kesehatan Lingkungan. Vol 2, No, Juli 2005 : $77-87$. 
Sutanto,R. 2002. Pertanian Organik Menuju Pertanian Alternatif dan Berkelanjutan. Kanisius. Jakarta.

liwow, C. Widjajanto, D., Darjamuni, dkk. 2003. Pengelolaan Sampah lerpadu sebagai Salah Satu Upaya
Mengatasi Problem Sampah di Perkotaan. Makalah Pengantar Sains. IPB.

lrubus $468.2008 . \quad$ Organik Lambungkan Panen. lrubus Swadaya. Jakarta. 